\title{
A phase III study of belagenpumatucel-L, an allogeneic tumor cell vaccine, as maintenance therapy for non-small cell lung cancer
}

G Giaccone $^{\mathrm{a}, 1,2}$, LA Bazhenova ${ }^{\mathrm{b}, 1}$, J Nemunaitis ${ }^{\mathrm{c}}$, Ming Tan ${ }^{\mathrm{d}}$, E Juhász ${ }^{\mathrm{e}}$, R Ramlau ${ }^{\mathrm{f}}$, MM van den Heuvel $^{\mathrm{g}}$, R Lal ${ }^{\mathrm{h}}$, GH Kloecker ${ }^{\mathrm{i}}$, KD Eaton ${ }^{\mathrm{j}}, \mathrm{Q} \mathrm{Chu}^{\mathrm{k}}$, DJ Dunlop ${ }^{1}$, M Jain ${ }^{\mathrm{m}}$, EB Garon ${ }^{\mathrm{n}}$, CS Davis ${ }^{\mathrm{o}}$, E Carrier $^{\mathrm{p}}$, SC Moses ${ }^{\mathrm{p}}$, DL Shawler ${ }^{\mathrm{p}}$, and H Fakhrai ${ }^{\mathrm{p}, 3}$.

Author's Affiliations: ${ }^{a}$ National Cancer Institute, Bethesda, MD, USA; ${ }^{b}$ Moores Cancer Center, UC San Diego, La Jolla, California, USA; ' Mary Crowley Cancer Research Centers, Dallas, Texas, USA; ${ }^{\mathrm{d}}$ Lombardi Comprehensive Cancer Center, Georgetown University, Washington DC, USA; ' Korányi National Institute for TB and Pulmonology, Budapest, Hungary; ${ }^{\mathrm{f}}$ Wielkopolskie Centrum Pulmonologii i Torakochirurgii, Poznań University of Medical Sciences, Poznan, Poland; ${ }^{\mathrm{g}}$ Netherlands Cancer Institution, Antoni Van Leeuwenhoek Hospital, Thoracic Oncology, Amsterdam, Netherlands; ${ }^{\mathrm{h}}$ Guy's Hospital, King's Health Partners, London, England, United Kingdom; ${ }^{i}$ James Graham Brown Cancer Center, University of Louisville, Louisville, Kentucky, USA; ${ }^{j}$ Seattle Cancer Care Alliance, University of Washington, Seattle, Washington, USA; ${ }^{k}$ Cross Cancer Institute, Edmonton, Alberta, Canada; ${ }^{1}$ Royal Infirmary, Glasgow, Scotland, United Kingdom; ${ }^{\mathrm{m}}$ Noble Hospital, Pune, India; ${ }^{\mathrm{n}}$ University of California, Los Angeles, Los Angeles, CA, USA; ${ }^{\circ}$ CSD Biostatistics, Tucson, AZ, USA, ${ }^{\mathrm{p}}$ NovaRx Corporation, San Diego, California, USA.

${ }^{1}$ Drs. Giaccone and Bazhenova are co-first authors for this publication.

2 current address: Lombardi Comprehensive Cancer Center, Georgetown University, Washington DC, USA.

${ }^{3}$ Dr. Habib Fakhrai is the sponsor of the trial and inventor of NovaRx technology.

Running Title: Maintenance Therapy for NSCLC with Belagenpumatucel-L.

Key Words: Non-small cell lung cancer, cancer vaccine, cancer immunotherapy, cancer gene therapy, TGF- $\beta$.

Corresponding Author: Giuseppe Giaccone, MD PhD

Lombardi Comprehensive Cancer Center

Georgetown University

3970 Reservoir Road

Washington DC 20007

Emailgg496@georgetown.edu 


\section{Abstract}

Background: Treatment options after first-line chemotherapy are limited in NSCLC. Belagenpumatucel-L is a therapeutic vaccine comprised of 4 TGF- $\beta 2$-antisense gene-modified, irradiated, allogeneic NSCLC cell lines that may be useful for maintenance after initial treatment.

Methods: Stage III/IV NSCLC patients who did not progress after platinum-based chemotherapy were randomized 1:1 to receive maintenance belagenpumatucel-L or placebo. Patients were eligible for randomization between one to four months from the end of induction chemotherapy. The primary endpoint was overall survival.

Results: This phase III trial enrolled 270 patients in the belagenpumatucel-L arm and 262 in the control arm. Belegenpumatucel-L was well tolerated with no serious safety concerns. There was no difference in survival between the arms (median survival 20.3 vs 17.8 months with belagenpumatucel-L vs. placebo, respectively; HR 0.94, $\mathrm{p}=0.594$ ). There were also no differences in progression-free survival (4.3 months vs 4.0 for belagenpumatucel-L vs placebo, respectively; HR 0.99, $\mathrm{p}=0.947)$. A prespecified Cox regression analysis demonstrated that the time elapsed between randomization and the end of induction chemotherapy had a significant impact on survival $(\mathrm{p}=0.002)$ and that prior radiation was a positive prognostic factor (median survival 28.4 months with belagenpumatucel-L vs. 16.0 months with placebo; HR 0.61, $\mathrm{p}=0.032$ ).

Conclusions: Although the overall trial did not meet its survival endpoint, improved survival for belagenpumatucel-L is suggested in patients who were randomized within 12 weeks of completion of chemotherapy and in those who had received prior radiation. Further studies of belagenpumatucel-L in NSCLC are warranted. 


\section{Introduction}

Lung cancer is the most prevalent cancer in the western world, with approximately 224,000 new cases and 159,000 deaths expected in the United States in 2014 (1), and 187,000 deaths in the European Union (2).

Most patients with advanced non-small cell lung cancer (NSCLC) are initially treated with four to six cycles of platinum-based doublet chemotherapy (3-5) but five-year survival of stage IIIB/IV patients is less than $10 \%$ (6). Patients without progression following frontline chemotherapy may be placed on maintenance therapy. Patients with non-squamous cell carcinoma who receive maintenance pemetrexed show a moderate survival benefit (7). Maintenance with erlotinib, a molecule targeting the epidermal growth factor receptor (EGFR), is approved for all NSCLC histologies (8), although it is most frequently used in EGFR mutant adenocarcinoma patients (3).

Immunotherapy trials performed in NSCLC have included whole tumor cell vaccines (9-12), single tumor-associated peptides such as MUC1, telomerase, epidermal growth factor, WT1 (1316), multiple tumor-associated peptides (17) and dendritic cells pulsed with tumor cells (18).

Belagenpumatucel-L is an allogeneic whole tumor cell vaccine comprised of four NSCLC cell lines that were transfected with a human TGF- $\beta 2$-antisense vector designated pCHEK/HBA2 (9, 10, 19). Two previous Phase II trials have demonstrated the safety and efficacy of belagenpumatucel-L in patients with $\operatorname{NSCLC}(9,10)$. We report on the results of a randomized, placebo-controlled Phase III study to investigate the efficacy of belagenpumatucel-L as a maintenance therapy in patients not progressing following frontline platinum-based chemotherapy. 


\section{Patients and Methods}

Study Design

Patients with advanced NSCLC were randomized to receive maintenance belagenpumatucel-L $\left(2.5 \times 10^{7}\right.$ cells per dose $)$ or placebo in a $1: 1$ ratio in this international, double blind, intention to treat (ITT) study (NCT00676507).

Inclusion criteria included histologically confirmed diagnosis of stage IIIA (T3N2), IIIB, or IV NSCLC (20). Patients had stable disease or response following up to 6 cycles of a platinumbased frontline chemotherapy regimen, with or without radiation therapy. Patients had to be 1875 years of age with an ECOG performance status of 0 , 1, or 2 and an estimated life expectancy of at least 12 weeks. Other eligibility criteria were hemoglobin $\geq 9 \mathrm{~g} / \mathrm{dL}$, albumin levels $\geq 2.5$ $\mathrm{g} / \mathrm{dL}$, bilirubin $\leq 1.5$ times the upper limit of normal (ULN), aspartate transaminase and alanine transaminase $\leq 1.5 \times \mathrm{ULN}$, creatinine $\leq 1.5 \times \mathrm{ULN}$, alkaline phosphatase $\leq 5 \times \mathrm{ULN}$. Patients were eligible to be randomized between one to four months ( 4 to 17.4 weeks) following the completion of frontline chemotherapy. Patients must not have received other antitumor therapies within four weeks of randomization.

Exclusion criteria included concurrent systemic steroids, bone metastases that required immediate therapy, uncontrolled pleural effusions, serious non-malignant disease, and previous malignancies unless in remission for $\geq 2$ years.

The protocol was approved by the Ethics Committee and the Institutional Biosafety Committee of each participating center. Written informed consent was obtained from each patient. The study was undertaken in accordance with the ethics principles of the Declaration of Helsinki and the Belmont Report, in compliance with the obligations and requirements of clinical investigators, and with ICH Good Clinical Practices guidelines and all applicable laws and regulations. This trial was registered at www.ClinicalTrials.gov with the trial registration ID of NCT00676507. 


\section{Randomization and Stratification}

An interactive voice-activated response system (IVRS) controlled patient randomization and stratification. Patients, investigators, study team members, and the sponsor were all blinded to the treatment assignment.

The Pocock and Simon minimization method (21) was used to randomize patients into treatment and control arms while accounting for the different strata. The patients were stratified by stage (IIIA vs. IIIB/IV), brain metastases, radiation during frontline chemotherapy, and bevacizumab during frontline chemotherapy.

\section{Procedures}

Patients were eligible to receive up to 20 cycles of treatment; 18 cycles of monthly intradermal injections followed by 2 quarterly cycles of intradermal injections. Patients were removed from treatment upon disease progression or physician/patient decision to receive other treatments. Off-treatment patients were followed for survival.

Belagenpumatucel-L is comprised of four NSCLC cell lines, SK-LU1/HBA2 (adenocarcinoma), H520/HBA2 (squamous cell carcinoma), RH2/HBA2 (squamous cell carcinoma), and H460/HBA/2 (large cell carcinoma). Each cell line was transfected by electroporation with TGF- $\beta 2$ antisense as previously described $(9,10)$. The cells were grown in adherent cultures under cGMP conditions. The cultures were harvested, irradiated with 10,000 cGy, and cryopreserved in Plasma-Lyte A (Baxter Healthcare, Marion, NC) containing 10\% human serum albumin (Baxter Healthcare, Westlake Village, CA) and 10\% dimethyl sulfoxide (DMSO; Bioniche Teo, Galway, Ireland). At the pharmacy the cells were thawed, mixed and $2.5 \times 10^{7}$ total cells were injected intradermally into the upper arm. Placebo consisted of $0.15 \%$ Intralipid $^{\circledR}$ in solution composed of the cryopreservation formulation minus the DMSO. 
The determination of tumor response to frontline chemotherapy was made by an independent radiology organization (World Care Clinical, Boston, MA) by comparing pre-randomization CT scans to end-of-chemotherapy scans. MRIs of the brain were also compared. If present, brain metastases must have been treated and remained stable for at least 2 months prior to study enrollment.

During the trial, patients were evaluated for using standard blood panels and chemistries, physical examination, and limited neurologic examinations. CT scans were performed every three months. For patients enrolled with stable brain metastases, MRI scans of the brain were performed every three months.

\section{Statistical Analyses}

The primary efficacy endpoint of this clinical trial was overall survival (OS) of patients randomized to belagenpumatucel-L compared to patients randomized to placebo. OS was calculated from the date of randomization to the date of death from any cause. Patients who were alive or lost-to-follow-up were censored at the last known date of contact. Survival distributions were estimated using Kaplan-Meier and the primary analysis was conducted using a two-sided log rank test. The trial was powered to detect a 3.5-month survival advantage for belagenpumatucel-L assuming a 10.5-month median OS for placebo (22). Two interim analyses were performed. The first interim analysis was performed after 140 events and the second was performed after 210 events. The overall type- 1 error rate was established at 0.0016 for the first interim analysis, 0.01 for the second interim analysis, and 0.046 for the final analysis. The analyses were performed by an independent data safety monitoring committee.

Secondary efficacy endpoints included progression-free survival (PFS) and tumor response by RECIST. The Statistical Analysis Plan also prespecified additional analyses using the Cox proportional hazards regression model to assess the influence of time elapsed from the end of frontline chemotherapy to randomization, histology, stage, prior radiation therapy, brain metastases, prior bevacizumab therapy, performance status, gender, age, clinical site, prior 
surgery, prior hormone therapy, prior immunotherapy, and prior steroid therapy on OS. Based on two other maintenance studies $(7,23)$ that limited enrollment to 6 and 12 weeks following the completion of frontline chemotherapy, time elapsed was categorized as less than or equal to 12 weeks (84 days) or greater than 12 weeks. 


\section{Results}

\section{Demographics}

This international, randomized, double-blind, placebo controlled study enrolled 532 patients in 73 centers in 8 countries between August 2008 and June 2012. The dataset was locked after the second interim analysis.

The belagenpumatucel-L and placebo arms were well balanced for baseline characteristics (Table 1). 220 patients (41.4\%) were randomized in North America, 284 patients (53.4\%) were randomized in Europe, and 28 patients (5.3\%) were randomized in India.

Overall Survival (OS)

The study was terminated at the second interim analysis for futility. The median ITT OS was 20.3 months (95\% CI, 16.8 - 23.7) for belagenpumatucel-L compared to 17.8 months (95\% CI, 13.7 - 22.0) for placebo (HR 0.94, 95\% CI, $0.73-1.20 ; \mathrm{p}=0.594$ ) (Figure 1A).

The OS and hazard ratios of the baseline characteristics, including the stratification criteria, are shown in Table 2. A prespecified Cox regression analysis showed a trend towards improved survival for patients who received belagenpumatucel-L within 12 weeks of the completion of frontline chemotherapy. No correlations with survival were seen with stage, presence of brain metastases, prior treatment with bevacizumab, age, gender, histology, or racial/ethnic background.

In the 318 patients who were randomized within 12 weeks of the completion of frontline chemotherapy (169 in the belagenpumatucel-L arm and 149 in the placebo arm) median OS for vaccine patients was 20.7 months (95\% CI 14.6-26.9) and median OS for placebo patients was 13.4 months (95\% CI 9.9-16.7) (HR 0.77, 95\% CI 0.56-1.05; $\mathrm{p}=0.092)$ (see Figure 1B). 
A prespecified analysis showed that patients who received chemoradiation therapy (chemoRT) prior to randomization demonstrated better survival in the belagenpumatucel-L arm. There were 161 patients who received chemoRT prior to randomization; 78 in the belagenpumatucel-L arm and 83 in the placebo arm. The main characteristics of these groups were well balanced. As shown in Figure 2A, median OS for vaccine patients was 28.4 months (95\% CI 14.1-42.7) versus 16.0 months (95\% CI 8.9-23.1) for placebo (HR 0.61, 95\% CI 0.38-0.96; $\mathrm{p}=0.032$ ). An exploratory analysis of survival in patients who received chemoRT prior to randomization and were randomized within 12 weeks included 84 patients, 46 in the belagenpumatucel-L arm and 38 in the placebo arm. Median OS for vaccine patients was 28.4 months (95\% CI 12.3-44.4) versus 10.3 months (95\% CI 7.7-12.8) for placebo (HR 0.47, 95\% CI $0.26-0.87 ; p=0.013$ ) (Figure 2B). Patients who received RT less than or equal to 6 months prior to randomization had better survival than patients who received RT more than 6 months prior, whereas in the placebo arm there was no difference between the two groups (Table 3).

\section{Secondary Endpoints}

There was no significant difference in PFS between the treatment arms. Median PFS was 4.3 months ( $95 \%$ CI, $3.4-5.2$ ) for belagenpumatucel-L compared to 4.0 months (95\% CI, $3.0-5.0$ ) for placebo (HR 0.99, $0.82-1.20 ; \mathrm{p}=0.947)$.

In the belagenpumatucel-L arm there were 6 documented partial responses and 1 documented complete response for a response rate of $2.5 \%$. In the placebo arm there was 1 documented partial response for a response rate of $0.4 \%$ ( $\mathrm{p}=0.123$; Fisher's exact test).

\section{Safety and Toxicity}

There were 81 serious adverse events (SAEs) reported; 49 in the belagenpumatucel-L arm and 32 in the placebo arm. Seventy-six (93.8\%) of these events were not drug-related as reported by the investigator. Five events were reported by the blinded investigator to be possibly or probably 
drug-related. One instance of cellulitis was reported in the control arm. Three instances of leptomeningeal carcinomatosis were reported, two in the belagenpumatucel-L arm and one in the control arm. Because these events occurred in both arms it is unclear that there was a relationship between the events and administration of belagenpumatucel-L.

There was one allergic reaction related to the administration of belagenpumatucel-L, characterized by a grade 2 rash on the upper body and arms, which appeared after injection 5 and was exacerbated by injection 6 a month later. The patient was removed from treatment and the event resolved a month later.

The grade 1 and 2 Adverse Events (AEs) that were reported more than 20 times are shown in Table 4.

Post-study Treatments

Table 5 shows a summary of the documented systemic anticancer therapies received after patients discontinued treatment on the study. 145 patients (54\%) in the belagenpumatucel-L cohort and 138 (53\%) in the control cohort received systemic anticancer therapy after withdrawl from the study. The most frequent agents used were pemetrexed, erlotinib, and docetaxel. 


\section{Discussion}

This large double-blind randomized study failed to demonstrate a significant increase in survival of belagenpumatucel-L as a maintenance therapy in the overall patient population with stage III/IV NSCLC who had stable disease after frontline therapy.

A prespecified Cox regression analysis suggests the importance of the time elapsed between completion of chemotherapy and randomization $(\mathrm{p}=0.002)$. Patients randomized within 12 weeks of the completion of frontline chemotherapy had 20.7-month median survival in the belagenpumatucel-L arm compared to 13.3-month median survival for the placebo arm $(\mathrm{p}=$ 0.092). Of the 532 patients enrolled in the trial, 214 (40\%) were randomized more than 12 weeks following the completion of frontline chemotherapy, raising the possibility that one reason why this trial did not meet the primary endpoint was due to late enrollment after induction therapy. These data do not control the inflated type I errors due to multiple testing and are therefore considered to be exploratory analyses.

Chemotherapy induces phenotypic changes in tumor cells, including upregulation of Fas, calreticulin, and MHC class I, that make cells more sensitive to lysis by cytotoxic T-lymphocytes (24-28). Enrollment of patients more than 12 weeks following induction may allow time for these effects to dissipate and for the tumor phenotype to revert to its less sensitive prechemotherapy condition (24-27).

Leukopenia induced by platinum-based chemotherapy regimens is one of the limiting toxicities for the treatment of NSCLC $(29,30)$. However, not all immune effector subsets are equally affected by chemotherapy and different subsets show different kinetics during and following chemotherapy $(24,31-34)$. Studies have shown a sustained depletion of the Foxp $3^{+} \mathrm{CD} 127^{\text {lo }}$ regulatory $\mathrm{T}$ cell subset (Tregs) following platinum-based chemotherapy $(24,28,33)$. Chemotherapy induces decreases in the ratio of Tregs to both $\mathrm{CD}^{+} \mathrm{T}$ cells $(24,31,34)$ and $\mathrm{CD}^{+} \mathrm{T}$ cells $(31,33,34)$. An increase in the Th1 subset of $\mathrm{T}$ cells has also been shown to coincide with the decrease in Tregs following platinum-based chemotherapy (31). All of these 
result in a beneficial antitumor immune environment that is associated with better survival (33). Randomizing patients more than 12 weeks following the completion of chemotherapy gives the Tregs time to regenerate and allows the immune system to revert to the immunosuppressive prechemotherapy state. Thus, our further evaluation of the study population within 12 weeks following the completion of chemotherapy to define optimal activity of belagenpumatucel-L is in line with other maintenance therapies $(7,23)$.

A prespecified analysis showed a survival advantage for patients who received chemoRT prior to receiving belagenpumatucel-L (HR 0.61, $\mathrm{p}=0.032)$. Tumor radiation exerts a number of effects that are beneficial for antitumor immunity (35). Radiation upregulates MHC class I, increases the pool of peptides presented by the class I molecules (36), and alters the phenotype of Tregs, which significantly impairs their immunosuppressive function (37). Although tumor radiation induces a significant reduction in both $\mathrm{T}$ and $\mathrm{B}$ cells, the reduction in Tregs is greater and more long lasting than in conventional $\mathrm{T}$ cells (38). Based on these observations, the association between prior radiation and survival on belagenpumatucel-L, which are consistent with data reported by the tecemotide (MUC1) vaccine (23), generate an important hypothesis for the further study of tumor vaccines and should be considered in the design of future immunotherapy vaccine protocols.

While the overall trial did not meet its prespecified endpoint, additional analyses summarized in this paper indicate encouraging results in predefined subsets of patients. Most importantly, a clinically meaningful increase in overall survival was observed in the belagenpumatucel-L arm for patients who were randomized within 12 weeks of the completion of frontline chemotherapy. Furthermore, prolongation of survival was most notable in patients who received chemoRT prior to randomization into this trial. Although the number of cases is small, a post-hoc analysis showed that the effect or radiation was observed in the belagenpumatucel-L arm only, when radiation was given 6 months or less before randomization. The toxicity profile of belagenpumatucel-L compares very favorably with that of the currently available maintenance therapies $(7,8)$. Based on the suggested survival benefits described above, a confirmatory study of belagenpumatucel-L in these patient populations is warranted. Exploratory studies of combination of belagenpumatucel-L and PD-1 or PDL-1 are also warranted. 


\section{Contributors}

Concept and design: Giuseppe Giaccone, Ewa Carrier, Steven C. Moses, Daniel L. Shawler, and Habib Fakhrai.

Assembly of data: Steven C. Moses, Daniel L. Shawler, and Habib Fakhrai.

Enrollment of patients: Giuseppe Giaccone. Lyudmila Bazhenova, John Nemunaitis, Erzsébet Juhász, Rodrig Ramlau, Michel M. van den Heuvel, Rohit Lal, Goetz H Kloecker, Keith D. Eaton, Quincy Chu, David J. Dunlop, Minish Jain, and Edward B. Garon.

Data Analysis and interpretation: Giuseppe Giaccone, Lyudmila Bazhenova, John Nemunaitis, Ming Tan, Charles S. Davis, Steven C. Moses, Daniel L. Shawler, and Habib Fakhrai.

Manuscript writing: Giuseppe Giaccone, Lyudmila, Bazhenova, John Nemunaitis, Rohit Lal, Quincy Chu, Edward B. Garon, Charles S. Davis, Ewa Carrier, Steven C. Moses, Daniel L. Shawler, and Habib Fakhrai.

Final approval of manuscript: All authors.

\section{Acknowledgements}

The trial was sponsored by NovaRx Corporation, San Diego, CA, USA. The trial was supported by SBIR grant R44 CA096025 (HF) and by NovaRx Corporation. 


\section{Reference List}

(1) Siegel R, Ma J, Zou Z, Jemal A. Cancer statistics, 2014. CA Cancer J Clin 2014 Jan, 64(1), 9-29.

(2) Malvezzi M, Bertuccio P, Levi F, La VC, Negri E. European cancer mortality predictions for the year 2013. Ann Oncol 2013 Mar,24(3), 792-800.

(3) National Comprehensive Cancer Network. NCCN guidelines non-small cell lung cancer, version 2.2013. NCCN Guidelines 2013,Accessed 2013.

(4) Socinski MA, Schell MJ, Peterman A, et al. Phase III trial comparing a defined duration of therapy versus continuous therapy followed by second-line therapy in advanced-stage IIIB/IV non-small-cell lung cancer. J Clin Oncol 2002 Mar 1,20(5), 1335-1343.

(5) Soon YY, Stockler MR, Askie LM, Boyer MJ. Duration of chemotherapy for advanced non-small-cell lung cancer: a systematic review and meta-analysis of randomized trials. $J$ Clin Oncol 2009 Jul 10,27(20), 3277-3283.

(6) Goldstraw P, Crowley J, Chansky K, et al. The IASLC Lung Cancer Staging Project: proposals for the revision of the TNM stage groupings in the forthcoming (seventh) edition of the TNM Classification of malignant tumours. J Thorac Oncol 2007 Aug,2(8), 706-714.

(7) Ciuleanu T, Brodowicz T, Zielinski C, et al. Maintenance pemetrexed plus best supportive care versus placebo plus best supportive care for non-small-cell lung cancer: a randomised, double-blind, phase 3 study. Lancet 2009 Oct 24,374(9699), 1432-1440.

(8) Cappuzzo F, Ciuleanu T, Stelmakh L, et al. Erlotinib as maintenance treatment in advanced non-small-cell lung cancer: a multicentre, randomised, placebo-controlled phase 3 study. Lancet Oncol 2010 Jun,11(6), 521-529.

(9) Nemunaitis J, Dillman RO, Schwarzenberger PO, et al. Phase II study of belagenpumatucel-L, a transforming growth factor beta-2 antisense gene-modified allogeneic tumor cell vaccine in non-small-cell lung cancer. J Clin Oncol 2006 Oct 10,24(29), 4721-4730.

(10) Nemunaitis J, Nemunaitis M, Senzer N, et al. Phase II trial of Belagenpumatucel-L, a TGF-beta2 antisense gene modified allogeneic tumor vaccine in advanced non small cell lung cancer (NSCLC) patients. Cancer Gene Ther 2009 Mar 13.

(11) Raez LE, Cassileth PA, Schlesselman JJ, et al. Allogeneic vaccination with a B7.1 HLAA gene-modified adenocarcinoma cell line in patients with advanced non-small-cell lung cancer. J Clin Oncol 2004,22(14), 2800-2807. 
(12) Nemunaitis J, Sterman D, Jablons D, et al. Granulocyte-macrophage colony-stimulating factor gene-modified autologous tumor vaccines in non-small-cell lung cancer. $J$ Natl Cancer Inst 2004 Feb 18,96(4), 326-331.

(13) Butts C, Murray N, Maksymiuk A, et al. Randomized phase IIB trial of BLP25 liposome vaccine in stage IIIB and IV non-small-cell lung cancer. J Clin Oncol 2005 Sep 20,23(27), 6674-6681.

(14) Bolonaki I, Kotsakis A, Papadimitraki E, et al. Vaccination of patients with advanced non-small-cell lung cancer with an optimized cryptic human telomerase reverse transcriptase peptide. J Clin Oncol 2007 Jul 1,25(19), 2727-2734.

(15) Neninger VE, de la Torre A, Osorio RM, et al. Phase II randomized controlled trial of an epidermal growth factor vaccine in advanced non-small-cell lung cancer. J Clin Oncol 2008 Mar 20,26(9), 1452-1458.

(16) Oka Y, Tsuboi A, Taguchi T, et al. Induction of WT1 (Wilms' tumor gene)-specific cytotoxic T lymphocytes by WT1 peptide vaccine and the resultant cancer regression. Proc Natl Acad Sci US A 2004 Sep 21,101(38), 13885-13890.

(17) Barve M, Bender J, Senzer N, et al. Induction of immune responses and clinical efficacy in a phase II trial of IDM-2101, a 10-epitope cytotoxic T-lymphocyte vaccine, in metastatic non-small-cell lung cancer. J Clin Oncol 2008 Sep 20,26(27), 4418-4425.

(18) Hirschowitz EA, Foody T, Kryscio R, Dickson L, Sturgill J, Yannelli J. Autologous dendritic cell vaccines for non-small-cell lung cancer. J Clin Oncol 2004,22(14), 28082815.

(19) Fakhrai H, Mantil JC, Liu L, et al. Phase I clinical trial of a TGF-beta antisense-modified tumor cell vaccine in patients with advanced glioma. Cancer Gene Ther 2006 Dec,13(12), 1052-1060.

(20) Sobin L, Wittekind C. TNM Classification of Malignant Tumours, Sixth Edition. New York, Wiley-Liss, 2002.

(21) Pocock SJ, Simon R. Sequential treatment assignment with balancing for prognostic factors in the controlled clinical trial. Biometrics 1975 Mar,31(1), 103-115.

(22) Stewart DJ. Update on the role of topotecan in the treatment of non-small cell lung cancer. Oncologist 2004,9 Suppl 6, 43-52.

(23) Butts C, Socinski MA, Mitchell PL, et al. Tecemotide (L-BLP25) versus placebo after chemoradiotherapy for stage III non-small-cell lung cancer (START): a randomised, double-blind, phase 3 trial. Lancet Oncol 2014 Jan,15(1), 59-68.

(24) Gameiro SR, Caballero JA, Higgins JP, Apelian D, Hodge JW. Exploitation of differential homeostatic proliferation of T-cell subsets following chemotherapy to 
enhance the efficacy of vaccine-mediated antitumor responses. Cancer Immunol Immunother 2011 Sep,60(9), 1227-1242.

(25) Gameiro SR, Caballero JA, Hodge JW. Defining the molecular signature of chemotherapy-mediated lung tumor phenotype modulation and increased susceptibility to T-cell killing. Cancer Biother Radiopharm 2012 Feb,27(1), 23-35.

(26) Papay J, Sapi Z, Egri G, et al. Platinum-based chemotherapy in lung cancer affects the expression of certain biomarkers including ERCC1. Pathol Oncol Res 2009 Sep,15(3), 445-450.

(27) Zitvogel L, Kepp O, Senovilla L, Menger L, Chaput N, Kroemer G. Immunogenic tumor cell death for optimal anticancer therapy: the calreticulin exposure pathway. Clin Cancer Res 2010 Jun 15,16(12), 3100-3104.

(28) Emens LA. Chemoimmunotherapy. Cancer J 2010 Jul,16(4), 295-303.

(29) Bretti S, Berruti A, Gorzegno G, et al. Multicenter Phase II trial of intermediate dose cisplatin and vinorelbine in inoperable non-small cell lung cancer patients. Lung Cancer 1996 Jun, 14(2-3), 353-360.

(30) Gebbia V, Galetta D, Lorusso V, et al. Cisplatin plus weekly vinorelbine versus cisplatin plus vinorelbine on days 1 and 8 in advanced non-small cell lung cancer: a prospective randomized phase III trial of the G.O.I.M. (Gruppo Oncologico Italia Meridionale). Lung Cancer 2008 Sep,61(3), 369-377.

(31) Wu X, Feng QM, Wang Y, Shi J, Ge HL, Di W. The immunologic aspects in advanced ovarian cancer patients treated with paclitaxel and carboplatin chemotherapy. Cancer Immunol Immunother 2010 Feb,59(2), 279-291.

(32) Huang X, Chen YT, Song HZ, Huang GC, Chen LB. Cisplatin pretreatment enhances anti-tumor activity of cytokine-induced killer cells. World J Gastroenterol 2011 Jul 7,17(25), 3002-3011.

(33) McCoy MJ, Lake RA, van der Most RG, Dick IM, Nowak AK. Post-chemotherapy T-cell recovery is a marker of improved survival in patients with advanced thoracic malignancies. Br J Cancer 2012 Sep 25,107(7), 1107-1115.

(34) Wu L, Yun Z, Tagawa T, Rey-McIntyre K, Anraku M, de PM. Tumor cell repopulation between cycles of chemotherapy is inhibited by regulatory T-cell depletion in a murine mesothelioma model. J Thorac Oncol 2011 Sep,6(9), 1578-1586.

(35) Multhoff G, Rodel F, Pockley AG, Gaipl US. Frontiers research topic: radiation-induced effects and the immune system. Front Oncol 2013,3, 55.

(36) Reits EA, Hodge JW, Herberts CA, et al. Radiation modulates the peptide repertoire, enhances MHC class I expression, and induces successful antitumor immunotherapy. $J$ Exp Med 2006 May 15,203(5), 1259-1271. 
(37) Cao M, Cabrera R, Xu Y, Liu C, Nelson D. Gamma irradiation alters the phenotype and function of CD4+CD25+ regulatory T cells. Cell Biol Int 2009 May,33(5), 565-571.

(38) Wei S, Egenti MU, Teitz-Tennenbaum S, Zou W, Chang AE. Effects of tumor irradiation on host T-regulatory cells and systemic immunity in the context of adoptive T-cell therapy in mice. J Immunother 2013 Feb,36(2), 124-132. 


\section{Tables}

Table 1. Demographics

\begin{tabular}{|c|c|c|c|c|c|c|}
\hline & \multicolumn{2}{|c|}{ All } & \multicolumn{2}{|c|}{$\leq 12 \mathrm{wks}$} & \multicolumn{2}{|c|}{$>12$ wks } \\
\hline Demographic & Vaccine & Control & Vaccine & Control & Vaccine & Control \\
\hline Enrolled & 270 & 262 & 169 & 149 & 100 & 109 \\
\hline $\begin{array}{l}\text { Age } \\
\text { Mean } \\
\text { Range } \\
\end{array}$ & $\begin{array}{c}61.5 \pm 8.5 \\
32-75\end{array}$ & $\begin{array}{c}60.5 \pm 8.5 \\
28-75\end{array}$ & $\begin{array}{c}61.2 \pm 8.6 \\
32-75\end{array}$ & $\begin{array}{c}60.6 \pm 9.2 \\
28-75\end{array}$ & $\begin{array}{c}60.2 \pm 8.2 \\
40-75\end{array}$ & $\begin{array}{c}60.6 \pm 7.6 \\
43-75\end{array}$ \\
\hline $\begin{array}{l}\text { Sex } \\
\quad \text { Male } \\
\text { Female } \\
\end{array}$ & $\begin{array}{l}156(58 \%) \\
114(42 \%)\end{array}$ & $\begin{array}{l}151(58 \%) \\
111(42 \%)\end{array}$ & $\begin{array}{c}102(60 \%) \\
67(40 \%)\end{array}$ & $\begin{array}{l}87(58 \%) \\
62(42 \%)\end{array}$ & $\begin{array}{l}54(54 \%) \\
46(46 \%)\end{array}$ & $\begin{array}{l}62(57 \%) \\
47(43 \%)\end{array}$ \\
\hline $\begin{array}{l}\text { Race } \\
\text { White } \\
\text { Black } \\
\text { Asian } \\
\text { Not specified }\end{array}$ & $\begin{array}{l}238(88 \%) \\
6(2 \%) \\
21(8 \%) \\
5(2 \%) \\
\end{array}$ & $\begin{array}{c}235(90 \%) \\
4(2 \%) \\
20(8 \%) \\
3(1 \%) \\
\end{array}$ & $\begin{array}{c}148(88 \%) \\
2(1 \%) \\
15(9 \%) \\
4(2 \%) \\
\end{array}$ & $\begin{array}{c}134(90 \%) \\
0(0 \%) \\
14(9 \%) \\
1(1 \%) \\
\end{array}$ & $\begin{array}{l}90(90 \%) \\
4(4 \%) \\
5(5 \%) \\
1(1 \%) \\
\end{array}$ & $\begin{array}{l}97(89 \%) \\
4(4 \%) \\
6(6 \%) \\
2(2 \%) \\
\end{array}$ \\
\hline $\begin{array}{l}\text { Ethnicity } \\
\text { Hispanic } \\
\text { Non-hispanic } \\
\end{array}$ & $\begin{array}{c}5(2 \%) \\
265(98 \%) \\
\end{array}$ & $\begin{array}{c}2(1 \%) \\
260(99 \%) \\
\end{array}$ & $\begin{array}{c}3(2 \%) \\
166(98 \%) \\
\end{array}$ & $\begin{array}{c}1(1 \%) \\
148(99 \%)\end{array}$ & $\begin{array}{c}2(2 \%) \\
98(98 \%) \\
\end{array}$ & $\begin{array}{c}1(1 \%) \\
108(99 \%) \\
\end{array}$ \\
\hline $\begin{array}{l}\text { Stage } \\
\text { Stage IIIA } \\
\text { Stage IIIB/IV } \\
\end{array}$ & $\begin{array}{r}22(8 \%) \\
248(92 \%) \\
\end{array}$ & $\begin{array}{c}20(8 \%) \\
242(92 \%) \\
\end{array}$ & $\begin{array}{c}7(4 \%) \\
162(96 \%) \\
\end{array}$ & $\begin{array}{c}6(4 \%) \\
143(96 \%) \\
\end{array}$ & $\begin{array}{l}15(15 \%) \\
85(85 \%) \\
\end{array}$ & $\begin{array}{l}12(11 \%) \\
97(89 \%) \\
\end{array}$ \\
\hline $\begin{array}{l}\text { Histology } \\
\text { Adenocarcinoma } \\
\text { Squamous } \\
\text { Large Cell } \\
\text { Adenosquamous carcinoma } \\
\text { Undifferentiated } \\
\text { Other or not specified }\end{array}$ & $\begin{array}{c}162(60 \%) \\
65(24 \%) \\
16(6 \%) \\
4(2 \%) \\
114(\%) \\
12(4 \%) \\
\end{array}$ & $\begin{array}{c}141(54 \%) \\
81(31 \%) \\
13(5 \%) \\
4(2 \%) \\
6(2 \%) \\
17(3 \%) \\
\end{array}$ & $\begin{array}{c}104(62 \%) \\
36(21 \%) \\
12(7 \%) \\
1(1 \%) \\
7(4 \%) \\
9(5 \%) \\
\end{array}$ & $\begin{array}{c}72(48 \%) \\
51(34 \%) \\
8(5 \%) \\
3(2 \%) \\
3(2 \%) \\
11(7 \%) \\
\end{array}$ & $\begin{array}{c}57(57 \%) \\
29(29 \%) \\
5(5 \%) \\
3(3 \%) \\
5(5 \%) \\
1(1 \%) \\
\end{array}$ & $\begin{array}{c}66(61 \%) \\
29(27 \%) \\
6(6 \%) \\
1(1 \%) \\
3(3 \%) \\
4(4 \%) \\
\end{array}$ \\
\hline $\begin{array}{l}\text { Performance Status } \\
\text { ECOG } 0 \\
\text { ECOG } 1 \\
\text { ECOG } 2 \\
\end{array}$ & $\begin{array}{c}119(44 \%) \\
139(51 \%) \\
7(3 \%) \\
\end{array}$ & $\begin{array}{c}130(50 \%) \\
119(45 \%) \\
6(2 \%) \\
\end{array}$ & $\begin{array}{c}80(47 \%) \\
82(49 \%) \\
5(3 \%)\end{array}$ & $\begin{array}{c}84(56 \%) \\
61(41 \%) \\
2(1 \%) \\
\end{array}$ & $\begin{array}{c}39(39 \%) \\
56(56 \%) \\
2(2 \%) \\
\end{array}$ & $\begin{array}{c}46(42 \%) \\
54(50 \%) \\
4(4 \%)\end{array}$ \\
\hline $\begin{array}{c}\text { Brain Metastases } \\
\text { Positive } \\
\text { Negative }\end{array}$ & $\begin{array}{c}19(7 \%) \\
251(93 \%)\end{array}$ & $\begin{array}{c}18(7 \%) \\
244(93 \%)\end{array}$ & $\begin{array}{c}15(9 \%) \\
154(91 \%)\end{array}$ & $\begin{array}{c}12(8 \%) \\
137(92 \%)\end{array}$ & $\begin{array}{c}4(4 \%) \\
96(96 \%)\end{array}$ & $\begin{array}{c}5(5 \%) \\
104(95 \%)\end{array}$ \\
\hline $\begin{array}{l}\text { Pre-randomization Therapies } \\
\text { Prior chemoRT } \\
\text { No prior chemoRT } \\
\end{array}$ & $\begin{array}{c}73(29 \%) \\
177(71 \%)\end{array}$ & $\begin{array}{c}63(27 \%) \\
174(73 \%)\end{array}$ & $\begin{array}{c}41(27 \%) \\
114(73 \%)\end{array}$ & $\begin{array}{c}29(21 \%) \\
110(79 \%)\end{array}$ & $\begin{array}{l}32(34 \%) \\
63(66 \%)\end{array}$ & $\begin{array}{l}34(35 \%) \\
63(65 \%)\end{array}$ \\
\hline $\begin{array}{l}\text { Prior bevacizumab } \\
\text { No prior bevacizumab }\end{array}$ & $\begin{array}{c}30(11 \%) \\
240(89 \%) \\
\end{array}$ & $\begin{array}{l}25(10 \%) \\
237(90 \%)\end{array}$ & $\begin{array}{c}19(11 \%) \\
150(89 \%) \\
\end{array}$ & $\begin{array}{c}16(11 \%) \\
133(89 \%) \\
\end{array}$ & $\begin{array}{l}11(11 \%) \\
89(89 \%) \\
\end{array}$ & $\begin{array}{c}8(7 \%) \\
101(93 \%) \\
\end{array}$ \\
\hline $\begin{array}{l}\text { Enrollment by Region } \\
\text { North America } \\
\text { Rest of the World }\end{array}$ & $\begin{array}{l}113(42 \%) \\
157(58 \%)\end{array}$ & $\begin{array}{l}107(41 \%) \\
155(59 \%)\end{array}$ & $\begin{array}{l}76(45 \%) \\
93(55 \%)\end{array}$ & $\begin{array}{l}59(40 \%) \\
90(60 \%)\end{array}$ & $\begin{array}{l}37(37 \%) \\
63(63 \%)\end{array}$ & $\begin{array}{l}44(40 \%) \\
65(60 \%)\end{array}$ \\
\hline
\end{tabular}


Table 2. Survival by Baseline Characteristics

\begin{tabular}{|c|c|c|c|c|c|c|}
\hline & \multicolumn{2}{|c|}{ Belagenpumatucel-L } & \multicolumn{2}{|c|}{ Placebo } & \multirow[b]{2}{*}{$\begin{array}{c}\text { Hazard } \\
\text { Ratio } \\
\end{array}$} & \multirow[b]{2}{*}{$95 \%$ CI } \\
\hline & N. & $\begin{array}{c}\text { Median } \\
\text { (months) }\end{array}$ & N. & $\begin{array}{c}\text { Median } \\
\text { (months) }\end{array}$ & & \\
\hline $\begin{array}{l}\text { Age group (years) } \\
\quad<65 \\
\geq 65\end{array}$ & $\begin{array}{l}156 \\
114 \\
\end{array}$ & $\begin{array}{l}19.9 \\
20.5 \\
\end{array}$ & $\begin{array}{c}167 \\
95 \\
\end{array}$ & $\begin{array}{l}19.0 \\
13.3 \\
\end{array}$ & $\begin{array}{l}1.00 \\
0.83 \\
\end{array}$ & $\begin{array}{l}0.73 \text { to } 1.37 \\
0.56 \text { to } 1.22\end{array}$ \\
\hline $\begin{array}{l}\text { Sex } \\
\quad \text { Male } \\
\text { Female } \\
\end{array}$ & $\begin{array}{l}156 \\
114 \\
\end{array}$ & $\begin{array}{l}17.3 \\
31.5 \\
\end{array}$ & $\begin{array}{l}151 \\
111 \\
\end{array}$ & $\begin{array}{l}16.4 \\
20.4 \\
\end{array}$ & $\begin{array}{l}0.94 \\
0.75 \\
\end{array}$ & $\begin{array}{l}0.68 \text { to } 1.28 \\
0.51 \text { to } 1.12\end{array}$ \\
\hline $\begin{array}{l}\text { Time elapsed following } \\
\text { frontline chemotherapy } \\
\quad \leq 12 \text { weeks } \\
>12 \text { weeks }\end{array}$ & $\begin{array}{l}169 \\
100\end{array}$ & $\begin{array}{l}20.7 \\
20.3 \\
\end{array}$ & $\begin{array}{l}149 \\
109 \\
\end{array}$ & $\begin{array}{l}13.3 \\
30.4 \\
\end{array}$ & $\begin{array}{l}0.77 \\
1.19 \\
\end{array}$ & $\begin{array}{l}0.56 \text { to } 1.05 \\
0.79 \text { to } 1.80\end{array}$ \\
\hline $\begin{array}{c}\text { ECOG } \\
0 \\
1 \\
2 \\
\end{array}$ & $\begin{array}{c}119 \\
139 \\
7 \\
\end{array}$ & $\begin{array}{l}23.3 \\
15.8 \\
12.0 \\
\end{array}$ & $\begin{array}{c}130 \\
119 \\
6 \\
\end{array}$ & $\begin{array}{l}20.4 \\
15.4 \\
24.1 \\
\end{array}$ & $\begin{array}{l}0.83 \\
0.98 \\
2.72 \\
\end{array}$ & $\begin{array}{l}0.57 \text { to } 1.21 \\
0.69 \text { to } 1.39 \\
0.52 \text { to } 14.3 \\
\end{array}$ \\
\hline $\begin{array}{l}\text { Histology } \\
\text { Adenocarcinoma } \\
\text { Squamous cell carcinoma } \\
\text { Large cell carcinoma } \\
\text { Other } \\
\end{array}$ & $\begin{array}{l}162 \\
65 \\
16 \\
16 \\
\end{array}$ & $\begin{array}{l}22.5 \\
17.7 \\
16.1 \\
13.8 \\
\end{array}$ & $\begin{array}{c}141 \\
81 \\
13 \\
12 \\
\end{array}$ & $\begin{array}{l}20.4 \\
15.2 \\
13.3 \\
\mathrm{NR}^{1} \\
\end{array}$ & $\begin{array}{l}0.92 \\
0.92 \\
0.69 \\
2.18 \\
\end{array}$ & $\begin{array}{l}0.66 \text { to } 1.29 \\
0.58 \text { to } 1.46 \\
0.26 \text { to } 1.79 \\
0.66 \text { to } 7.14 \\
\end{array}$ \\
\hline $\begin{array}{l}\text { Stage } \\
\text { IIIA } \\
\text { IIIB } \\
\text { IV } \\
\end{array}$ & $\begin{array}{c}22 \\
67 \\
178 \\
\end{array}$ & $\begin{array}{l}15.5 \\
36.9 \\
20.2 \\
\end{array}$ & $\begin{array}{c}20 \\
68 \\
172 \\
\end{array}$ & $\begin{array}{l}30.4 \\
17.9 \\
16.2 \\
\end{array}$ & $\begin{array}{l}1.44 \\
0.88 \\
0.91 \\
\end{array}$ & $\begin{array}{l}0.61 \text { to } 3.37 \\
0.52 \text { to } 1.48 \\
0.68 \text { to } 1.23 \\
\end{array}$ \\
\hline $\begin{array}{c}\text { Brain metastases } \\
\text { Positive } \\
\text { Negative }\end{array}$ & $\begin{array}{c}19 \\
251\end{array}$ & $\begin{array}{l}13.5 \\
20.7\end{array}$ & $\begin{array}{c}18 \\
244\end{array}$ & $\begin{array}{c}7.2 \\
17.9\end{array}$ & $\begin{array}{l}0.66 \\
0.95\end{array}$ & $\begin{array}{l}0.28 \text { to } 1.53 \\
0.74 \text { to } 1.23\end{array}$ \\
\hline $\begin{array}{l}\text { Pre-randomization Therapies } \\
\text { Prior ChemoRT } \\
\text { No Prior ChemoRT } \\
\text { Prior bevacizumab } \\
\text { No prior bevacizumab } \\
\end{array}$ & $\begin{array}{c}73 \\
177 \\
30 \\
240 \\
\end{array}$ & $\begin{array}{l}23.5 \\
20.3 \\
40.1 \\
18.4 \\
\end{array}$ & $\begin{array}{c}63 \\
174 \\
25 \\
237 \\
\end{array}$ & $\begin{array}{l}15.1 \\
17.2 \\
20.4 \\
17.2 \\
\end{array}$ & $\begin{array}{l}0.83 \\
0.94 \\
0.65 \\
0.98 \\
\end{array}$ & $\begin{array}{l}0.51 \text { to } 1.33 \\
0.69 \text { to } 1.28 \\
0.29 \text { to } 1.46 \\
0.76 \text { to } 1.27 \\
\end{array}$ \\
\hline
\end{tabular}


Table 3. Effect of time from prior radiation to randomization.

\begin{tabular}{llcccc} 
Cohort & Radiation Therapy & $\mathbf{N}$ & Median OS & p Value & HR \\
\hline Vaccine & $\leq 6$ months before randomization & 34 & 40.1 & 0.040 & 0.41 \\
& $>6$ months before randomization & 13 & 14.8 & & \\
& & & & & \\
Placebo & $\leq 6$ months before randomization & 32 & 9.1 & 0.972 & 0.98
\end{tabular}


Table 4. Grade 1 and 2 Adverse Events

\begin{tabular}{|lcccc|}
\hline AE & Vaccine & Placebo & Total & p Value \\
\hline Arthralgia & 29 & 31 & 60 & NS \\
Back pain & 28 & 22 & 50 & NS \\
Cough & 71 & 65 & 136 & NS \\
Decreased appetite & 32 & 16 & 48 & 0.023 \\
Erythema & 35 & 7 & 42 & $<0.001$ \\
Extremity pain & 21 & 15 & 36 & NS \\
Fatigue & 66 & 54 & 120 & NS \\
Headache & 48 & 28 & 76 & 0.025 \\
Induration & 22 & 4 & 26 & $<0.001$ \\
Injection site reaction & 260 & 62 & 322 & $<0.001$ \\
Musculoskeletal pain & 34 & 21 & 55 & NS \\
Nasopharyngitis & 26 & 11 & 37 & 0.017 \\
Nausea & 40 & 36 & 76 & NS \\
Non-cardiac chest pain & 23 & 9 & 32 & 0.017 \\
Pyrexia & 25 & 17 & 42 & NS \\
Rash & 23 & 10 & 33 & 0.030 \\
Respiratory tract infection & 33 & 28 & 61 & NS \\
\hline
\end{tabular}


Table 5. Post-study Treatments

\begin{tabular}{|lcc|}
\hline Therapy & Belagenpumatucel-L & Control \\
\hline Any systemic anticancer therapy & $145(54 \%)$ & $138(53 \%)$ \\
Any combination therapy & $43(16 \%)$ & $51(19 \%)$ \\
Carboplatin & $24(9 \%)$ & $20(8 \%)$ \\
Cisplatin & $10(4 \%)$ & $12(5 \%)$ \\
Pemetrexed & $35(13 \%)$ & $37(14 \%)$ \\
Erlotinib & $32(12 \%)$ & $29(11 \%)$ \\
Docetaxel & $31(11 \%)$ & $25(10 \%)$ \\
Paclitaxel & $8(3 \%)$ & $7(3 \%)$ \\
Gemcitabine & $17(6 \%)$ & $16(6 \%)$ \\
Gefitinib & $6(2 \%)$ & $2(1 \%)$ \\
Vinorelbine & $5(2 \%)$ & $7(3 \%)$ \\
Bevacizumab & $6(2 \%)$ & $9(3 \%)$ \\
\hline
\end{tabular}




\section{Figure Legends}

Figure 1. Kaplan-Meier analyses of overall survival. A. Overall ITT survival in all patients $(\mathrm{N}=532)$. B. Overall survival of patients randomized within 12 weeks of the completion of frontline chemotherapy $(\mathrm{N}=318)$. Survival in the Lucanix arm is shown in blue. Survival in the placebo arm is shown in red.

Figure 2. A. Overall survival in patients who received chemoRT during frontline chemotherapy $(\mathrm{N}=161)$. B. Overall survival in patients randomized within 12 weeks of the completion of frontline chemotherapy who received chemoRT during frontline chemotherapy $(\mathrm{N}=84)$. Survival in the Lucanix arm is shown in blue. Survival in the placebo arm is shown in red. 
Figures

Figure 1

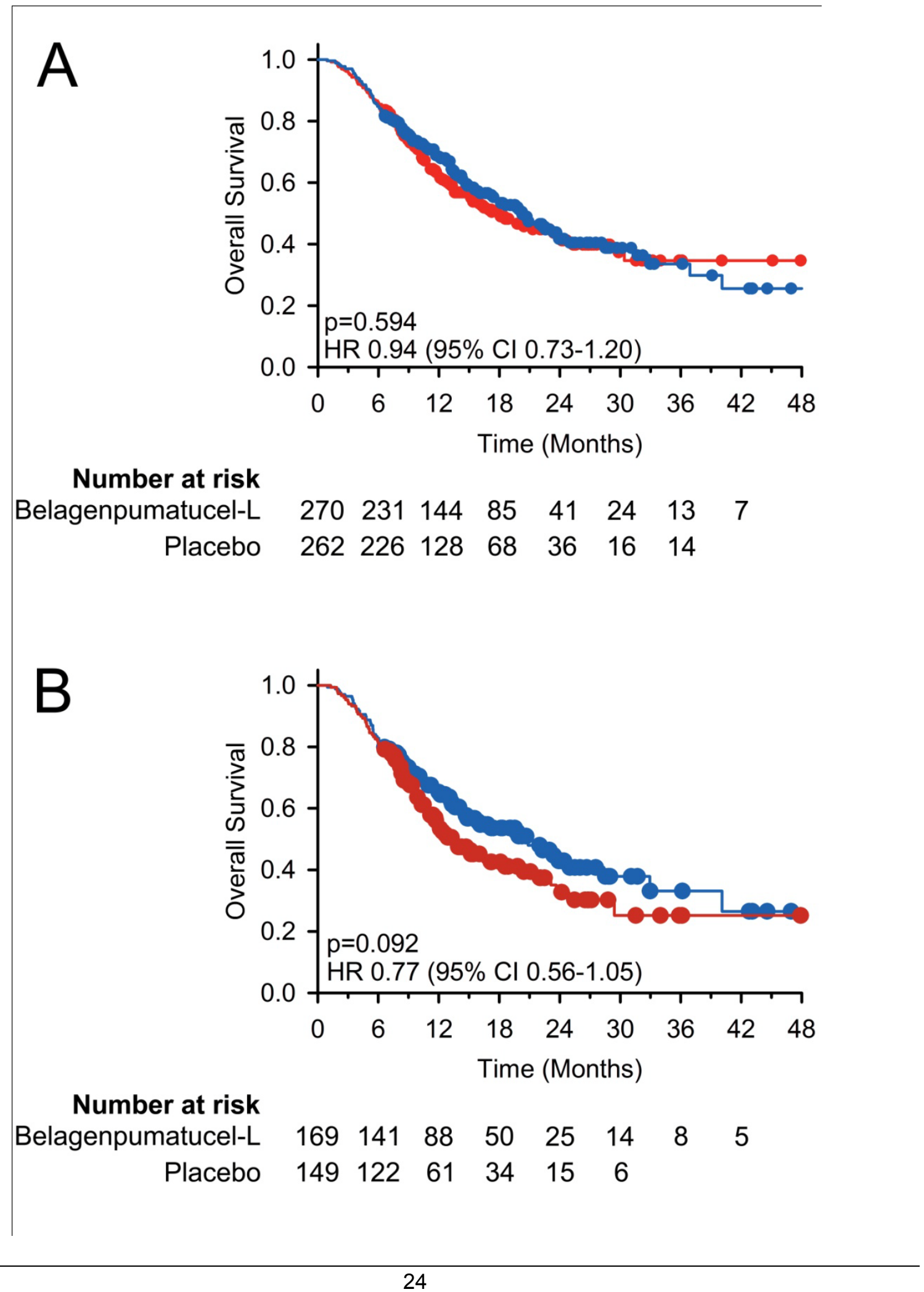


Figure 2

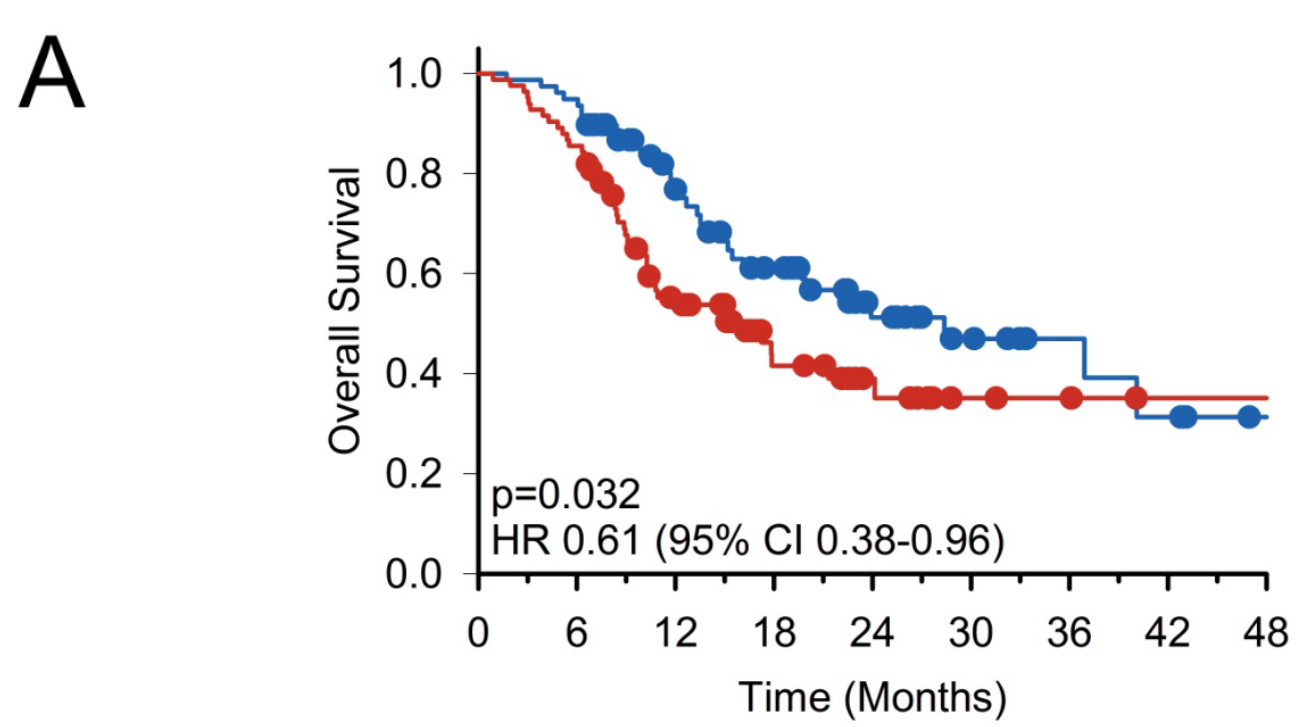

Number at risk

$\begin{array}{lllllllll}\text { Belagenpumatucel-L } & 78 & 75 & 48 & 35 & 18 & 12 & 12 & 5\end{array}$

$\begin{array}{llllll}\text { Placebo } & 83 & 72 & 38 & 19 & 10\end{array}$

B

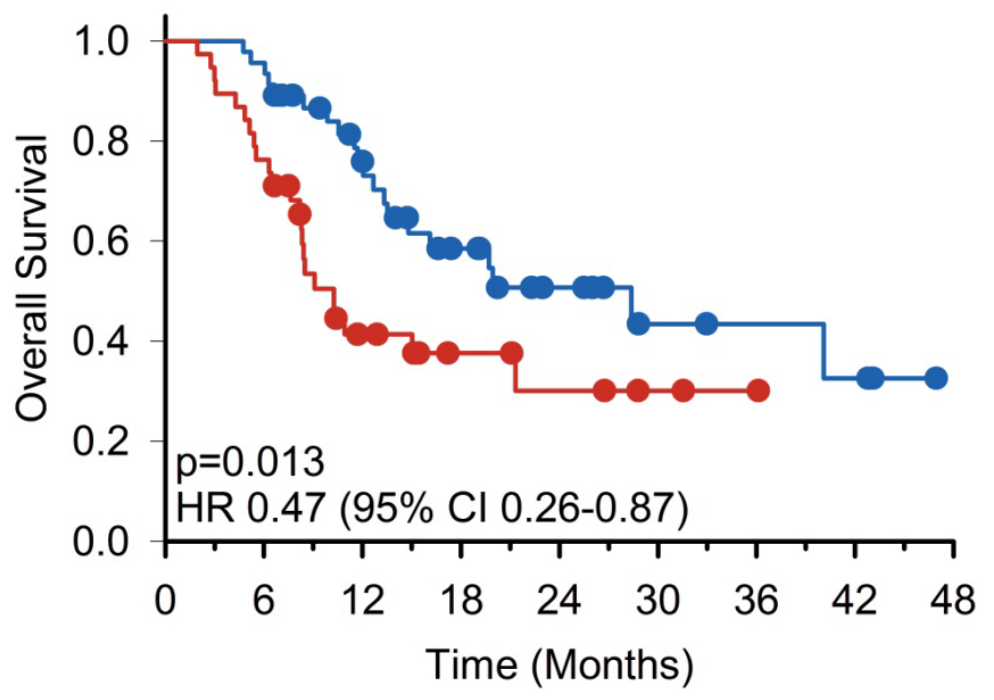

Number at risk

$\begin{array}{lllllllll}\text { Belagenpumatucel-L } & 46 & 45 & 29 & 20 & 14 & 7 & 7 & 4\end{array}$

$\begin{array}{llllll}\text { Placebo } & 38 & 30 & 14 & 11 & 5\end{array}$ 